\title{
Ideas para una acción coordinada en restauración de monumentos arquitectónicos
}

Roberto Montandón ${ }^{1}$

\section{Introducción}

Sin apartarnos del respeto que debemos hacia todas las expresiones de la cultura, podemos decir que es a través del patrimonio arquitectónico, marco omnipresente de nuestra vida, que se establece, de manera natural e intensa, el diálogo vivido diariamente entre ayer y hoy. Es por su intermedio que se materializa el sentimiento, fundamental para el equilibrio del hombre, de la presencia del pasado, de la continuidad de la raza, de su cultura, de su inteligencia y de su creatividad. Así, este patrimonio, ilustre o modesto heredado de sus antepasados es, para la mayor parte de los pueblos, el vector más visible de su identidad y su conservación constituye hoy en día una preocupación universal.

El siglo XIX vio nacer en Inglaterra, Francia e Italia los primeros movimientos concertados, consagrados a la restauración de monumentos. Buscan su inspiración en consideraciones estéticas, morales, filosóficas, románticas y crean escuelas que cobijan teorías distintas: la arqueológica guiada por Ruskin, la interpretativa creada por Viollet le Duc y la científica, defendida por Giovannoni.

Pero la idea conceptual de que los pueblos deben reconocerse solidariamente responsables de la conservación del patrimonio arquitectónico ante las generaciones futuras, se abre paso y se fortalece lentamente en los primeros decenios de este siglo. A partir de los principios fundamentales adoptados por la Conferencia de Atenas en 1931 y bajo el impulso de la evolución del pensamiento sobre esta disciplina, se crean o se perfeccionan la doctrina, los métodos, la legislación, las estructuras administrativas, las técnicas de restauración.

La conferencia de Atenas marca una evolución en la manera de abordar la selección, las técnicas y

1 Universidad de Chile, Santiago, CHILE. los criterios en la tarea de proteger y restaurar los monumentos históricos. Pero la complejidad de los problemas pertinentes a esta disciplina y las divergencias que pronto emergieron aconsejaron una revisión de lo meditado y de lo hecho. Así, el Segundo Congreso de Arquitectos y de Técnicos en monumentos históricos, reunidos en Venecia en mayo de 1964, aprobó un texto de quince puntos conocido como la Carta de Venecia, que tuvo como fin primordial el de unificar los criterios de restauración.

La Carta de Venecia, que no es un dogma sino una etapa del pensamiento frente a la protección del patrimonio arquitectónico, será entregada a nuevas reflexiones en el Congreso Internacional que se celebrará en Basilea, Suiza, en marzo de 1983.

En el plano de los resortes y mecanismos que habrían de mover a los gobiernos en el ámbito de la salvaguardia del patrimonio arquitectónico, se destaca desde hace unos tres decenios la acción de Instituciones Internacionales que, en esa lucha, han demostrado una singular constancia y fuerza de decisión: UNESCO, OEA, Consejo de Europa, Consejo Internacional de Monumentos y Sitios (ICOMOS), Centro Internacional para la Conservación y la Restauración de los Bienes Culturales (ICCROM).

Pero, entre la Conferencia de Atenas y la Carta de Venecia, se abre paso un nuevo concepto que amplía la idea del Patrimonio arquitectónico y urbanístico y el ámbito de protección. Ya no sólo el monumento grandioso es digno de respeto; interviene su entorno, las casas tradicionales que lo rodean y le comunican el carácter ambiental; interviene también una visión más ancha de la arquitectura y de su escala de valores: los conjuntos urbanos o rurales, es decir sectores homogéneos en cuanto al estilo de sus edificaciones. La Asamblea Consultivo del Consejo de Europa recomienda, en 1963 y como tarea urgente, salvaguardar la aportación de los conjuntos al Patrimonio cultural de cada nación. La Asamblea los define así: Los conjuntos históricos y artísticos 
son constituidos por un grupo de construcciones aisladas o reunidas, cuya arquitectura, unidad o integración, presentan un carácter que justifica su protección y valorización.

Tendríamos así configurado lo que podríamos denominar el espacio histórico. Luego, este concepto se amplía y se extiende a la protección de los conjuntos históricos industriales, mineros y agrícolas y ya se maneja el término "arqueología industrial". Es cierto que la defensa de entornos y espacios históricos plantea problemas, complejos algunos, como su trasfondo socioeconómico, su revitalizacion, su protección jurídica, la integración al medio ambiente de una eventual aparición de una arquitectura contemporánea.

\section{Legislación y políticas de protección}

En nuestro país, la protección del patrimonio arquitectónico que hasta ahora se ha movido dentro de un ámbito centralizado tiende, como consecuencia de la regionalización, a constituir problemas regionales. Un proyecto de reforma de la ley de Monumentos Nacionales, ley que hasta ahora ha sido el principal cuerpo jurídico de protección del patrimonio arquitectónico y arqueológico, entrega a las Municipalidades instrumentos legales que aseguran su plena participación en beneficio de la conservación y restauración de los inmuebles registrados o declarados monumentos, ubicados en sus respectivas comunas. Estas medidas de protección del patrimonio histórico y artístico de la comuna serían incorporadas a la formulacion, ejecución y fiscalización de la política del plan de desarrollo comunal. El proyecto establece los mecanismos que regulan la estrecha vinculación que deberá existir entre los municipios y el Consejo de Monumentos Nacionales. De hecho, la participación de los gobiernos regionales representados por Intendentes, Gobernadores y Alcaldes se ha manifestado en los últimos años a través del financiamiento de varias obras de restauracion, de la solución de problemas urbanos que afectan la conservación del patrimonio histórico y de una preocupación creciente por la protección general de ese patrimonio cultural. Personalmente y dentro de las políticas generales de desarrollo regional, no me cabe la menor duda del importante papel que en adelante y en este campo desempeñarán los municipios. En el plano de una acción coordinada, esta responsabilidad traspasada se perfila como una invitación a una fructífera asociación entre los municipios y los organismos regionales llamados, por su saber, a participar en el desarrollo de su región.
La legislación que en el mundo protege el patrimonio arquitectónico es variadísimo; todas, con mayor o menor fluidez, persiguen el mismo objetivo. Su aplicación se ejerce de acuerdo al régimen a que el país pertenece: unitario, federal o cantonal, pero no importando la escala de delegación de responsabilidades y el respeto de las autonomías regionales, la doctrina, amparada por un régimen de derecho que protege el patrimonio cultural de una nación, se cobija bajo un alero central fiscalizador y protector, aun de esas corporaciones privadas que en los países anglosajones desarrollan la más extraordinaria de las labores de defensa y rescate del patrimonio arquitectónico y paisajístico.

Hoy en día, las políticas de carácter general para la conservación de monumentos y sitios históricos si bien ya lo subrayan (por conocida) la importancia del inventario como tarea prioritaria y previa a todas las planificaciones de salvaguardia del patrimonio arquitectónico y cultural, vuelven a llamar la atención sobre los peligros que acechan a este patrimonio: la insuficiencia de especialistas en este campo, la ausencia en la educación, de la enseñanza sobre la cultura y la arquitectura. ¿Estamos en Chile?, no, estamos en una conferencia mundial sobre las políticas culturales de la UNESCO, celebrada en México en agosto de 1982.

En general, las diferentes políticas enunciadas en diversas ocasiones constituyen, a través de sus recomendaciones, un verdadero programa de acción y configuran una actitud. Están de acuerdo en recomendar la sensibilización de la juventud en edad escolar hacia el Patrimonio Nacional, una participación activa de la población, una legislación en permanente perfeccionamiento, apropiada para la defensa de la arquitectura vernácula, de los conjuntos arquitectónicos, de pueblos enteros, una cooperación cultural estrecha a nivel nacional, internacional y mundial, una ampliación más adecuada de los medios financieros nacionales.

\section{Arquitectura vernácula}

Este tipo de arquitectura es predominante en el Patrimonio de la II Región. Por su extensión, requerirá la mayor atención y el mayor cuidado en los programas de conservación. En las zonas desérticas, esas casas de arquitectura doméstica están generalmente agrupadas en aldeas; son modestas y de enorme interés. Se identifican con sus habitantes y con el paisaje. De adobes bien cocidos al sol del 
desierto, bien asentadas en la tierra y con refuerzos del duro algarrobo, son, frente a su protección, de una extrema fragilidad y el que las estudia o restaura debe penetrar en el pensamiento de sus moradores. No es solo un tipo de arquitectura que se preserva, es un tipo de cultura. Enlaza, amarra la función de la vivienda con la función del trabajo rural y a menudo, esta arquitectura vernácula, con sus dos elementos prioritarios: el material y la escala, es refugio de la lengua vernácula. Esta arquitectura que responde a las exigencias específicas de la región, acoge las consolidaciones, reparaciones y limpiezas pero no admite cambios formales; destruirían su identidad. El inventario del patrimonio cultural de la región debe incluir una tipología de estas expresiones vernáculas.

\section{Arquitectura industrial y agricultura}

Este patrimonio que conjuga la arquitectura, la ingeniería y la técnica, presente también en la II Región, está recibiendo en el mundo cada vez mayor atención, al descubrirse los valores existentes en estaciones de ferrocarriles, fábricas, puentes, explotaciones mineras, muelles, molinos y lagares. Su inventario entra en el campo de la técnica especializada, como así su restauración. Por el alto interés que representa para la historia regional, su salvaguardia debe defenderse con la mayor energía.

\section{El inventario}

Es una especialidad. Persigue, como lo hemos señalado muchas veces, dos objetivos básicos: a) el conocimiento real y sistemático de los valores culturales que se debieran conservar o registrar para su investigación y estudio; b) la protección de esos valores. El proceso posterior de evaluación y factibilidad clasifica los resultados con criterio selectivo. Una metodología guía todo el proceso del inventario.

\section{La conservación del patrimonio arquitectónico y urbanístico como tarea especializada e interdisciplinaria}

Para hacer frente a la variedad de los problemas que derivan de los programas de conservación de este patrimonio y de los lazos que entre ellos existen, se tiende gradualmente a resolverlos formando equipos compuestos de diversos técnicos que tienen un grado de especialización y entrenamiento en la materia: arquitectos, urbanistas, restauradores, ingenieros, historiadores, arqueólogos, sociólogos, economistas y paisajistas. La vocación de un experto en restauración nace de una actitud mental y su entrenamiento técnico descansa en una formación paralela humanista e histórica. A su grado de sensibilidad, al conocimiento de las antiguas técnicas y de los materiales, a su capacidad de diagnóstico, a su manejo de la legislación se suma, para el arquitecto, el dominio de la arquitectura contemporánea y sus técnicas.

El dominio del oficio del experto se encuentra en la profundidad de su experiencia y el camino de la experiencia es largo.

Esta preparación profesional vería mermada su eficiencia si no contara con un cuerpo de gente del oficio. Considerando que la orientación actual de las técnicas en arquitectura amenazan con la desaparición progresiva de la mayor parte de los antiguos oficios de la construcción, se recomienda formar un registro de jefes de obra, artesanos y obreros familiarizados con las técnicas tradicionales.

\section{La acción coordinadora}

Espero que esta incursión por algunos de los mecanismos que articulan los principios clásicos de la protección del patrimonio arquitectónico conduzca a una etapa de reflexión previa a la elaboración, sin sorpresas, de un programa regional de acción coordinada para la restauración de monumentos. Por otra parte, quisiera recordar que la restauración constituye en sí una etapa feliz del largo y permanente proceso que conduce a la protección del patrimonio.

La formación de cuerpos regionales consagrados a la exploración, estudio, defensa y restauración del patrimonio regional, carecería de momento de una base jurídica; el Consejo de Monumentos Nacionales no delega atribuciones. Podrían tener un alcance académico de alta importancia, su mando los recursos intelectuales y técnicos de las dos universidades de la II Región. No obstante, para entrar en el campo de las realizaciones prácticas, la mejor opción sea tal vez la constitución de una corporación de derecho privado, sin fines de lucro, dedicada a promover y coordinar en todos sus aspectos, la protección y restauración del patrimonio arquitectónico y arqueológico de la región, a desarrollar los estudios e investigaciones tendientes al mejor conocimiento de este vasto campo del saber y del hacer, a formar restauradores regionales partiendo 
de la experiencia existente y del cultivo, en ambas universidades, de disciplinas bases (arquitectura, arqueología), a divulgar y publicar sus trabajos y a establecer en esta materia intercambios nacionales e internacionales.

Dentro de la más estricta observancia de la legislación vigente, esta corporación, amparada por las dos universidades, fortalecida por la institución de vínculos con el gobierno regional, provincial o comunal, podría desarrollar una labor que abarcaría la suma de las medidas de conservación del patrimonio de la región. Anualmente, los recursos de origen regional (y comunal) destinados a la protección del patrimonio arquitectónico y arqueológico financiarían los estudios encomendados por las autoridades a la corporación, realizados de hecho por especialistas de ambas universidades.

Veo a esta corporación sin fines de lucro, pero financiada en sus costos, como un centro generador de una permanente acción a favor de la defensa del patrimonio arquitectónico y arqueológico regional.
La creación de una comisión regional podría presentarse como alternativa a la fórmula de la corporación. Esta comisión emergería como una herramienta propia del Gobierno Regional. No tendría la misma flexibilidad que la corporación, como tampoco su rango de acción. Desempeñaría la función de un cuerpo consultivo y asesor, importante, útil, aunque de campo restringido.

No olvidemos que cualquier programa de acción coordinado debe basarse en una muy clara idea conceptual de la conservación del patrimonio arquitectónico, urbanístico y arqueológico, en un realista estudio de factibilidad y en una honesta evaluación de las capacidades regionales y su pleno aprovechamiento.

Finalmente me permito recordar que el concepto de conservación y de restauración del patrimonio arquitectónico ha ido evolucionando. Propone un programa delicado, por cuanto este concepto no es definible de acuerdo a reglas fijas o rígidas, sino que requiere de la aplicación de criterios flexibles, gobernados por la prudencia y el sentido común. 